\title{
A HORA DA ESTRELA DE CINEMA: A NARRATIVA ENTRE A PÁGINA E A TELA
}

\section{THE HOUR OF THE MOVIE STAR: NARRATIVE BETWEEN PAGE AND SCREEN}

\author{
Rony Márcio Cardoso FERREIRA ${ }^{1}$
}

\begin{abstract}
Resumo: O presente artigo visa a um estudo comparativo entre a novela A hora da estrela (1977), de Clarice Lispector, e o filme A hora da estrela (1985), de direção de Suzana Amaral. Apesar de já estabelecida no cenário crítico, essa comparação, distinta de outras, objetiva evidenciar em que medida alguns aspectos narrativos da conhecida novela são traduzidos e transcriados na linguagem cinematográfica. Para tanto, este estudo parte de uma breve reflexão sobre a importância contemporânea do caráter não disciplinar das teorias sem disciplinas e de uma explanação sobre a relação entre literatura e cinema. Valeremo-nos dos postulados teóricos defendidos por Claus Clüver (1977; 2006), Thaïs Diniz (2005), Paulo Emílio Gomes (2007), entre outros, bem como apresentaremos uma análise das escolhas feitas por Suzana Amaral na adaptação da novela, com o intuito de abordar a produção da cineasta enquanto objeto artístico singular e específico que promove uma "sobrevida" (DERRIDA, 2002; BENJAMIN, 2008) da obra de Lispector, por meio de uma renovação que contribuiu para sua permanência em nossa tradição cultural.
\end{abstract}

Palavras-chave: Literatura. Cinema. Adaptação. Tradução. Sobrevida.

\begin{abstract}
This article aims to compare the novel The Hour of the Star (1977) by Clarice Lispector, and the Brazilian film A hora da estrela (1985) directed by Suzana Amaral. Although already established in the critical scenario, this comparison, different from others, aims to highlight to which extent some narrative aspects of the literary novel are translated and transcribed to the cinema. Thus, this study starts with a reflection on the contemporary importance of the non-disciplinary character of the theories without disciplines for the establishment of the relations between literature and cinema, through the theoretical postulates defended by Claus Clüver (1977, 2006), Thaïs Diniz (2005), Paulo Emílio Gomes (2007), among others. In addition, it presents an analysis of the choices made by Amaral when adapting Lispector's novel, aiming to approach the production of the filmmaker as a singular and specific artistic object that promotes a "survival" (DERRIDA, 2002; BENJAMIN, 2008) of Lispector's work, through a renovation that contributed to its permanence in our cultural tradition.
\end{abstract}

Keywords: Literature. Cinema. Adaptation. Translation. Survival.

\section{Os estudos interartes e o espaço das teorias sem disciplina}

Teorias sin disciplina [...] poderia ser uma das saídas para a complexa discussão sobre o campo disciplinar contemporâneo (SOUZA, 2007, p. 151).

\footnotetext{
${ }^{1}$ Doutor em Literatura pela Universidade de Brasília (UnB). Professor dos Cursos de Graduação em Letras da Universidade Estadual de Mato Grosso do Sul (UEMS), campus de Campo Grande. E-mail:
} Revista Graphos, Vol. 20 n. 1, 2018 | UFPB/PPGL | ISSN 1516-1536 
A epígrafe acima traz à pauta da discussão crítica uma questão que pulula, sem muitos esforços, no âmbito acadêmico contemporâneo: as "não-disciplinas" que prefiguram o cenário da crítica, nesta primeira parte do século XXI. Essa questão sempre esteve, de uma forma ou de outra, presente nos estudos das humanidades em geral, talvez travestida pela rubrica "interdisciplinaridade", a qual concedeu novos rumos aos estudos literários, artísticos, filosóficos, psicanalíticos, sociológicos, para citarmos apenas alguns. Diante disso, o campo das inter-relações epistêmicas alastrou-se de maneira significativa, fazendo com que uma nova rubrica passasse a designar o fenômeno. Ao invés de "inter", prefixo que supõe a relação entre duas disciplinas, entrou na ordem reflexiva do dia o prefixo "trans", partícula que quis se pôr para "além de" qualquer seguimento disciplinar.

Por meio dessas reordenações, pensando em particular no campo de investigação voltado à linguagem artística, tornou-se possível que distintos discursos teóricos, antes tomados como autossuficientes, se auxiliassem de forma mútua na abordagem crítica de um mesmo objeto. Em outras palavras, disciplinas específicas como a teoria da literatura, a teoria da arte e a teoria da comunicação, entre outras, abriram seus leques investigativos no tocante à abordagem de seus objetos de análise. Contudo, devemos ressaltar que, na maioria das vezes, ainda preponderava, no discurso crítico, um campo epistemológico centralizador para a dissecação dos objetos.

Com o passar do tempo, surgiram reflexões teóricas que iluminaram problemas investigativos de áreas comuns. Essas teorias, por não pertencerem restrita e exclusivamente a uma disciplina, passaram a configurar um grupo, contemporaneamente, designado por teorias sin disciplinas ${ }^{2}$. Estar para além dos muros disciplinares possibilitou ao crítico voltado a essas teorias uma inclinação investigativa que transpusesse questões inerentes a um só objeto de estudo e a uma só área do conhecimento. Estava, então, instaurada a necessária base da babel teórica e conceitual que caracterizaria o pensamento contemporâneo. Assim, como construção sempre a terminar e aberta ao futuro, a multiplicidade babélica do conhecimento possibilitou, de forma mais lúcida, o estabelecimento de inter-relações que aproximam (e distanciam) objetos e teorias, afastando qualquer traço de subalternidade antes existente entre eles.

Delimitando o campo de estudo para o qual convergem essas reflexões iniciais, faz-se necessário lembrar, longe de repeti-las como lições inquestionáveis, das importantes inferências sobre as relações interartes estabelecidas por René Wellek e Austin Warren, em

\footnotetext{
${ }^{2}$ Cf. SOUZA, 2007, p. 151.

Revista Graphos, Vol. 20 n. 1, 2018 | UFPB/PPGL | ISSN 1516-1536
} 
Teoria da Literatura (1949). Os estudiosos afirmaram, logo no início do capítulo "Literatura e outras artes", que as relações instauradas entre os textos literários e outros meios artísticos proporcionaram ao crítico um "largo campo de investigação"3 que merece um crédito especial. Observando as insistentes proposições que verificaram a mútua relação de efeitos produzidos a partir da comparação de distintos objetos artísticos (literatura, música, pintura, escultura, arquitetura, cinema, entre outros), restou à crítica do século XXI legitimar a contribuição dos estudiosos quanto à "estreita relação entre as artes" (WELLEK; WARREN, s.d., p. 154). Contudo, devemos salientar que, apesar dessa contribuição, o discurso dos autores encontrava-se ainda marcado por um forte teor disciplinar - "afigura-se arriscado interpretar a pintura à luz da filosofia contemporânea" (WELLEK; WARREN, s.d., p. 159) -, perspectiva que não poderia ser diferente naquele contexto.

Ao traçar uma espécie de paralelismo entre alguns objetos artísticos, Wellek e Warren sugeriram que estudos dessa natureza estariam para uma abordagem mais extrínseca do texto, enquanto o estudioso da literatura deveria, na perspectiva dos críticos, se ocupar com seu estudo intrínseco. Assim, a relação só poderia ser estabelecida a partir de um denominador comum pertencente a ambas as artes, mais especificamente, o elemento a ser relacionado deveria estar nos "textos" comparados (leia-se o termo "texto" como as artes em geral, porém é importante esclarecer que os autores de Teoria da Literatura não usam tal termo com esse sentido).

Claus Clüver (1997), ao “delimitar” alguns princípios que regem os estudos interartes da última virada de século, demonstrou a possibilidade de se estabelecer relações ainda que estas não estejam de todo presentes nos textos relacionados. Porém, Clüver também não descartou a possibilidade de comparação a partir de um elemento intertextual que o próprio texto sugere, pois "questões de intertextualidade podem fazer dos textos literários objetos propícios para os estudos interartes - o que não vale apenas para textos literários ou simplesmente verbais" (CLÜVER, 1997, p. 40). Nessa passagem, o estudioso, ainda que sutilmente, parece ampliar o conceito de intertextualidade tal como cunhado por Julia Kristeva em 1969. Se antes o conceito pensado a partir do dialogismo bakhtiniano era frutífero para designar o processo de "produtividade" do texto em suas múltiplas relações,

\footnotetext{
${ }^{3}$ Cf. WELLEK; WARREN, s.d., p. 154.

Revista Graphos, Vol. 20 n. 1, 2018 | UFPB/PPGL | ISSN 1516-1536
} 
como propõe a definição ${ }^{4}$, o termo agora parece abranger não só a "produtividade" do texto literário, como também a dos textos não-verbais.

Apesar da importante contribuição de Kristeva para os estudos literários, torna-se operante salientar que tal conceito está, de certa forma, muito ligado às questões intrínsecas ao próprio texto, ou seja, a intertextualidade parece "brotar" de determinado texto porque ela foi arquitetada no momento de sua produção. Aqui está o outro ponto que Clüver procura ampliar a partir da evocação da figura do leitor na identificação das relações intertextuais. Em suas palavras,

Tais questões de intertextualidade preocupam-se mais com a produção e a recepção do que com os próprios textos: os traços intertextuais que descobrimos e que nos remetem a uma miríade de pré-textos não dependem tanto do que está "no texto", $e$ sim do nosso próprio repertório de textos e hábitos de leitura (CLÜVER, 1997, p. 40 - grifo nosso).

O repertório de textos e os hábitos de leituras dos quais fala Clüver aproximam-se, ressalvadas as diferenças, do que Hans Robert Jauss (1994) entende por horizonte de expectativa do leitor. Desse modo, o que Clüver parece deixar claro é que as inter-relações entre objetos artísticos poderão ser estabelecidas a partir de semelhanças e diferenças evocadas na esfera da recepção. Se Jauss colocou a "entidade leitor" no centro de suas teses para pensar uma nova história da literatura ${ }^{5}$, Clüver evoca, bem a seu modo, essa mesma "entidade" como mola propulsora no estabelecimento de possíveis comparações entre as artes. É evidente que os postulados da Estética da recepção, principalmente aqueles advindos da teoria de Jauss, pressupõem um "leitor ideal", enquanto Clüver, a nosso ver, está atravessado por uma concepção de leitor, no mínimo, mais abrangente, uma vez que em sua perspectiva “as comunidades interpretativas [...] influenciam também o repertório textual e o horizonte de expectativa. Mas o repertório é, em última análise, parte dos contextos culturais nos quais se realizam a produção e a recepção textual” (CLÜVER, 2006, p. 15). Assim, dependendo do repertório do crítico, o que teríamos, segundo Clüver, seriam leituras singulares, devido ao contexto em que está submerso o saber prévio do crítico enquanto leitor, pois

Os modos de recepção ou "leitura" de textos verbais, visuais e musicais dependem muito, é claro, da educação e formação de cada indivíduo; dependem de hábitos fomentados pelas comunidades interpretativas (que podem não coincidir para cada

\footnotetext{
${ }^{4}$ Cf. KRISTEVA apud CARVALHAL, 2003, p. 72.

${ }^{5}$ Cf. JAUSS, 1994, p. $24-57$.

Revista Graphos, Vol. 20 n. 1, 2018 | UFPB/PPGL | ISSN 1516-1536
} 
uma das artes), bem como das condições e contextos de recepção dos textos (CLÜVER, 1997, p. 41).

O estatuto da recepção passa a configurar, por isso, o espaço-tempo a partir do qual as aproximações se tornam possíveis. Alicerçados nesses argumentos, os estudos interartes, assim como apresentados por Clüver, souberam se valer de teorias que a princípio se pensavam aplicáveis a um só objeto e a um específico campo epistemológico. Em outras palavras, podemos dizer que teorias da intertextualidade e da recepção, com todas as alterações necessárias, migraram de um lugar específico para configurar o novo espaço epistêmico, designado, incialmente, como estudos interartes. Entretanto, essa designação suscitou grande debate no cenário crítico, talvez porque tais estudos trouxeram em seu bojo uma articulação das teorias sem disciplinas. Isso não pressupõe que esse recente campo do saber esteja marcado por uma ausência de um pensamento crítico próprio, mas que teorias antes específicas a um campo disciplinar (literatura, pintura, cinema, escultura, arquitetura, música, entre outros) passaram a auxiliar o crítico na abordagem múltipla dos objetos artísticos.

Clüver, tratando da canção como um fenômeno a ser estudado por diversas vertentes e disciplinas, reitera a singularidade dos estudos interartes frente ao tradicional espaço acadêmico das humanidades, pois, na cena acadêmica, não existe um lugar epistêmico em que a canção possa ser estudada em sua exclusividade e completude, fato esse que proporciona aos críticos das artes a possibilidade de "desenvolver modos de lidar com um fenômeno como a canção, tão profundamente arraigada em todas as culturas" (CLÜVER, 1997, p. 49). Logo, os estudos interartes, enquanto modos de lidar com as diferentes linguagens, ampliam a possibilidade de comparação entre as artes, instaurando, ao mesmo tempo, um campo reflexivo para além dos já conhecidos e consagrados espaços disciplinares. Essa espécie de não-lugar ocupado por tais estudos fez com que a crítica os concebesse mais "como um discurso transdisciplinar às voltas com 'as artes' e suas inter-relações do que como uma disciplina autônoma" (CLÜVER, 1997, p. 52).

Esse discurso sustentou-se enquanto tal a partir de um conjunto de teorias sem disciplinas e viu-se marcado por um método a ser estabelecido de acordo com a origem científica daquele que faz a descrição/relação. Em vista disso, seria mais coerente falarmos em "métodos" dos estudos interartes, uma vez que, como discurso transdisciplinar, seu método não se define pela exclusividade, mas sim pela coexistência de critérios múltiplos 
empregados pelo crítico a partir de suas orientações prévias, ou seja, "um historiador de arte ou um musicólogo levantará questões diferentes em relação a um objeto de pesquisa intermidiática do que um teórico de cinema ou um comparativista" (CLÜVER, 2006, 17 grifo nosso), além de proceder metodologicamente de outra forma. Clüver corrobora, assim, o postulado incialmente defendido no texto de 1997, reiterando que a mais apropriada delimitação metodológica para a pesquisa interartes seria, em suma, aquela que salienta os plurais “modos de lidar" com os fenômenos artísticos em suas múltiplas relações ${ }^{6}$, isto é

\begin{abstract}
Os métodos dependerão, em boa medida, das questões que formularmos e das metas que seguiremos; tal como a literatura comparada, os estudos interartes não possuem metodologia própria. A terminologia terá que superar dois obstáculos sérios: o uso denotativo versus o uso figurativo de termos e a aplicação do mesmo termo a fenômenos em textos pictoriais, musicais e verbais que são necessariamente idênticos, análogos ou equivalentes em cada uma dessas áreas (CLÜVER, 1997, p. 53).
\end{abstract}

A alusão ao comparatismo literário no fragmento de Clüver parece fazer todo sentido, tendo em vista que esse campo dos estudos literários, ainda que sólido no espaço acadêmico, suscita controvérsias quando o assunto é a especificidade de seu objeto e método de estudo. Como bem afirma Sandra Nitrini (2000), em Literatura comparada, essa questão, ininterrupta há mais de um século, levou estudiosos e críticos a um eterno retorno reflexivo ${ }^{7}$, direcionando o comparatismo a uma orientação geral, no mínimo, multimetodológica. Esse fenômeno observado pelos críticos literários também esteve presente quando se procurou delimitar a área de atuação do estudioso das relações interartes. A partir dessas considerações iniciais, este artigo se volta a uma aproximação entre literatura e cinema, por meio de uma análise comparativa entre a novela $A$ hora da estrela (1977), de Clarice Lispector, e o filme $A$ hora da estrela (1986), de direção de Suzana Amaral.

\title{
A literatura e o cinema: aproximações transcriativas
}

[...] ninguém pensa que as obras e os cantos poderiam ser criados do nada. Eles estão sempre ali, no presente imóvel da memória. Quem se interessaria por uma palavra nova, não transmitida? O que importa não é dizer, mas redizer e, nesse redito, dizer a cada vez, ainda, uma primeira vez (BLANCHOT apud COMPAGNON, 1996, p. 6).

\footnotetext{
${ }^{6}$ Cf. CLÜVER, 1997, p. 49.

${ }^{7}$ Cf. NITRINI, 2000, 23.
}

Revista Graphos, Vol. 20 n. 1, 2018 | UFPB/PPGL | ISSN 1516-1536 
Os estudos entre cinema e literatura se tornaram pontos de reflexões importantes no diapasão científico das linguagens. Talvez isso se deva porque, com o passar dos tempos, os estudiosos tenham percebido com maior lucidez crítica o frutífero e vantajoso processo ao qual os cineastas sempre se dedicaram (de uma forma ou de outra), desde o surgimento do cinema: a adaptação. Tal processo só veio a reiterar o que no âmbito reflexivo parece ser ponto pacífico: a inter e transtextualidade presente em todo texto se estabelece em íntima relação com textos predecessores, contemporâneos ou sucessores. Ampliando essa perspectiva, podemos dizer que, se no campo teórico essa questão somente ficou clara com postulados críticos do século XX, na esfera das artes, essa relação foi sempre levada a cabo de diferentes maneiras, corroborando o fato de que, mesmo antes do surgimento do termo cunhado por Julia Kristeva, toda arte já se punha enquanto constructo de uma dimensão intertextual.

Anelise Corseuil (2009), na esteira dos estudos narratológicos, reconhece que todo processo de adaptação instaura uma relação intertextual ${ }^{8}$ entre a obra adaptada e o filme que surge, uma vez que tal processo se efetiva por meio de seleção, ampliação, concretização, atualização, crítica, exploração, analogização, popularização e recontextualização jamais inocentes, pois, toda correspondência intertextual está distante de “[...] uma hierarquização de valores, podendo o filme ser analisado em todas as suas modificações ideológicas, técnicas, críticas e interpretativas, partes integrantes de qualquer processo de adaptação" (CORSEUIL, 2009, p. 372 - grifo nosso). Sob essa égide, afasta-se do campo reflexivo qualquer estabelecimento de fidelidade entre os objetos comparados, no intuito de salientar a correspondência entre as artes, ao invés de um equivocado vínculo de dependência entre elas.

Nessa perspectiva, Thais F. N. Diniz (2005) apresenta-nos três enfoques de abordagem nos estudos sobre adaptação do texto literário para o cinema. Apesar de ser um "termo" genérico (adaptação), frequentemente empregado para rubricar a transposição narrativa efetuada pelo cinema com relação ao texto literário, os estudos de adaptação vêm mostrando que esse "deslocamento" de uma narrativa a outro suporte implica entrever, logo de antemão, a existência de várias formas de transposição de um texto, as quais, por sua vez, estão para além de critérios como o de fidelidade e equivalência, como pensou até certo tempo a crítica que se voltava a esse fenômeno. Conforme Diniz,

\footnotetext{
${ }^{8}$ Cf. CORSEUIL, 2009, p. 372.

Revista Graphos, Vol. 20 n. 1, 2018 | UFPB/PPGL | ISSN 1516-1536
} 
Houve uma mudança no enfoque dos estudos sobre adaptação, que agora enfatiza os elementos fílmicos, usando a comparação para enriquecer a avaliação do filme e não o contrário. A crítica passou a basear-se "na espécie de adaptação que o filme se propõe a ser" (McFarlane) e não na suposição de que só existe uma maneira de adaptar uma obra literária (DINIZ, 2005, p. 15).

Diniz (2005) afirma que um desses enfoques é aquele que visa ao estudo da adaptação como tradução. Proveniente da teoria da adaptação de Brian McFarlane, essa proposta centrase no exame da tarefa da adaptação a partir de um viés narratológico. O outro enfoque aborda a adaptação como uma reciclagem (James Naremore), pois vê, no recontar da história, que o filme se propõe a transportar uma espécie de dialogismo intertextual, isto é, seu enfoque baseia-se na ideia de que "todo texto forma uma interseção de superfícies textuais, tecidos de fórmulas anônimas, variações nessas fórmulas, citações conscientes e inconscientes, conflações e inversões de outros textos" (NAREMORE apud DINIZ, 2005, p. 17). O terceiro enfoque apresentado pela estudiosa é aquele defendido por Timothy Corrigan, que propõe uma abordagem mais culturalista, na qual se deve salientar não só a tradução que o cineasta efetuou, como também "a contextualização histórica, a questão das hierarquias culturais tradicionais, o processo de adaptação em si e a intertextualidade” (DINIZ, 2005, p. 16).

É escusado dizer da importância que cada uma dessas perspectivas possui quando nos voltamos para o estudo da adaptação cinematográfica. Reconhecemos, entretanto, assim como afirma Diniz, que o objeto a ser analisado (o filme), em sua relação direta com o texto de partida, já sinaliza de certo modo o tipo de adaptação a que o filme se propõe a ser ${ }^{9}$, indicando ao crítico o caminho a ser percorrido em uma possível compreensão e análise do processo de transposição. Muitos estudos rejeitam tomar a adaptação enquanto "tradução", devido à carga pejorativa que este termo carregou consigo ao longo dos séculos, como se a tarefa do tradutor se restringisse, basicamente, a uma reprodução mecânica, sustentada por um alto grau de fidedignidade a um texto anterior, resultando esse trabalho em uma obra de segunda mão, infiel e, por conseguinte, menor.

Vale ressaltar que essa rejeição se deve ao fato de que a tradição ocidental viu por muito tempo a tradução como um mecanismo de equivalência, visada essa já revista no seio dos contemporâneos estudos da tradução. Devido à instabilidade conceitual que marca a própria noção de equivalência, a ideia de tradução tem passado por reformulações consideráveis, principalmente após o pensamento da "desconstrução" (DERRIDA, 1998, p. 20), da

${ }^{9}$ Cf. DINIZ, 2005, p. 15.

Revista Graphos, Vol. 20 n. 1, 2018 | UFPB/PPGL | ISSN 1516-1536 
"transcriação" (CAMPOS, 2010, p. 35) e da "tradução cultural” (BHABHA, 1998, p. 308 315), para citarmos apenas alguns. Depois dessas contribuições, grosso modo, a imagem espectral da fidelidade é afastada e, por conseguinte, a noção de dívida da obra posterior questionada em contextos tradutórios. Ampliação também aplicável, a nosso ver, ao campo da adaptação cinematográfica, quando entendida como uma modalidade de tradução.

Pensando mais pontualmente no filme $A$ hora da estrela, a perspectiva mais coerente à proposta efetuada pela cineasta Suzana Amaral é a da adaptação como tradução, uma vez que vemos transposta, no filme de 1985, “a narrativa de uma história pré-existente através dos recursos do cinema [...], a tradução intersemiótica, de uma obra concebida no sistema verbal para um outro sistema de signos, o cinemático" (DINIZ, 2005, p. 34). Apesar de Diniz afirmar que a proposta da adaptação como tradução traz à tona, quase sempre, uma procura de equivalências entre as artes comparadas ${ }^{10}$, em $A$ hora da estrela, dirigido por Amaral, toda a narrativa do filme "traduz", entre aproximações e distanciamentos, uma das narrativas do livro de Lispector ${ }^{11}$. Dizemos com certa proximidade devido aos limites bem demarcados que diferenciam a arte cinematográfica da literária, pois, ainda que falemos em tradução no filme de Suzana Amaral, são inegáveis os elementos específicos das duas linguagens em comparação. Ou seja,

[...] existem outras diferenças que produzem certas limitações a cada meio: enquanto um filme é exibido em um teatro, pelo tempo médio de duas horas de duração, um romance pode ser lido durante horas, dias ou meses - fato que impossibilita qualquer adaptação literal de um longo romance [...]. Da mesma forma que o cinema apresenta certas limitações, um romance não dispõe de trilha sonora ou da simultaneidade de leitura, proporcionada pelas imagens projetadas em uma tela, o que possibilita uma leitura não linear da história narrada. A construção do espaço narrativo no cinema, com uma plenitude de detalhes visuais, constitui um espaço físico literal e figurativo diferente daquele apresentado no texto literário (CORSEUIL, 2009, p. 370).

Diniz (2005), além de evidenciar a função narrativa inerente ao cinema e à literatura, salienta, de modo semelhante a Corseuil (2009), que cada uma dessas artes utiliza recursos distintos para que a narrativa seja recontada e crie os efeitos esperados sobre o espectador.

\footnotetext{
${ }^{10}$ Diniz alega que, sob esse crivo, “[...] a tradução seria defendida como um processo de procura de equivalentes, ou melhor, de procura de um signo em outro signo semiótico, o cinema, que tenha a mesma função que o signo no primeiro sistema, a literatura" (DINIZ, 2005, p. 19). Entretanto, cabe pontuar que talvez esteja presente, no discurso de Diniz, uma noção de equivalência tal como contestada pelos estudos da tradução, visto que há "[...] muitas razões para se admitir que a equivalência não seja um conceito [...] estável" (PYM, 2017, p. 13).

${ }^{11}$ Segundo Benedito Nunes, a novela de Clarice Lispector, conjuga três histórias. A primeira seria a narrativa da moça nordestina (Macabéa), a segunda a do narrador interposto (Rodrigo S.M.) e a terceira a história da própria narrativa, a escritura que se problematiza (Cf. NUNES, 1995, p. 161 - 162).
}

Revista Graphos, Vol. 20 n. 1, 2018 | UFPB/PPGL | ISSN 1516-1536 
Diniz apresenta dois pontos principais para essa diferenciação: enquanto o meio de expressão na literatura é a linguagem verbal, o cinema, além dessa linguagem, dispõe de outros meios, como, por exemplo, a música e a imagem visual. Se esses diversos meios (linguagem verbal escrita e oral, a música, a imagem visual, entre outros) podem conceder ao cinema maiores possibilidades de "traduzir" determinados aspectos, a estudiosa também reitera que existem efeitos menos acessíveis à linguagem cinematográfica. $\mathrm{O}$ pensamento seria um deles ${ }^{12}$.

Quando pensamos em tradução no filme de Amaral, não estamos pressupondo categorias equivocadas como as de equivalência e fidedignidade, as quais, por sua vez, já se encontram muito bem revisadas e desconstruídas quando nos lembramos dos processos de tradução, sejam eles no âmbito linguístico ou nas relações entre as diferentes artes. Nesse sentido,

[...] não se trata, evidentemente, de uma tradução que almeje transportar ou comunicar conteúdos do "original" [...]. Seu propósito não é restituir os sentidos "maiores" e "inclassificáveis" das obras traduzidas. Ao contrário, traduzir, nesse caso, significa experimentar, recriar, contar de outro modo (SAID, 2005, p. 14 grifo nosso).

É sob a égide desse recriar que se executa a tradução/adaptação no filme $A$ hora $d a$ estrela, pois a cineasta reconta uma narrativa anterior, lançando mão de escolhas nada inocentes, fazendo de sua obra um objeto artístico singular, porém associável a outro. Aliás, para o espectador desinformado sobre o processo de adaptação e leigo quanto ao texto do qual se "origina" a narrativa, a obra cinematográfica deixa de ser, como tantas outras, associada a uma enganosa noção de cópia imperfeita. Na verdade, questões como cópia, imitação e alusão são processos que, nas artes em geral, já perderam o caráter pejorativo, pois, como uma vez afirmara Machado de Assis, em Esaú e Jacó (2005): “as próprias ideias nem sempre conservam o nome do pai; muitas parecem órfãs, nascidas de nada e de ninguém. Cada um pega delas, verte-as como pode, e vai levá-las à feira, onde todos as têm por suas” (ASSIS, 2005, p. 71).

\section{A hora da estrela de cinema: a narrativa entre o texto e a tela}

\footnotetext{
${ }^{12}$ Cf. DINIZ, 2005, p. 21-22.

Revista Graphos, Vol. 20 n. 1, 2018 | UFPB/PPGL | ISSN 1516-1536
} 
[...] na hora da morte a pessoa se torna brilhante estrela de cinema, é o instante da glória de cada um e é quando como no canto coral se ouvem agudos sibilantes (LISPECTOR, 1984, p. 36).

Essa epígrafe ilustra, com certa intensidade, o ápice narrativo da novela de Clarice Lispector, representado pelo angustiante fato cujo narrador Rodrigo S.M. é "obrigado a narrar" "13, ainda que não queira: os momentos "homéricos" da vida de Macabéa, os quais se direcionam para a hora da estrela da anti-heroína, para a hora da morte da pobre moça. Além disso, a mesma epígrafe evidencia que, ao morrer, a datilógrafa virgem que gosta de CocaCola se transforma em estrela de cinema, como estreante de um grande espetáculo. Por isso, para o narrador interposto, a hora da morte é vista como o momento de glória que todos têm, até os miseráveis, pois é o instante singular do brilho de um só ser.

As palavras de escritora reproduzidas em epígrafe também evidenciam que sua narrativa sugere uma espécie de cena cinematográfica, na qual a protagonista morre, sublimando-se como uma estrela brilhante enquanto um coro musical entoa uma sinfonia, concomitantemente. É notório que essa sequência narrativa é apenas sugerida pelo texto literário, cabendo ao leitor a sua projeção visual. Se pensássemos na arte cinematográfica, essa mesma cena talvez não precisasse de toda uma construção por parte do espectador, já que nessa linguagem, ao mesmo tempo, a personagem pode morrer, tornar-se estrela e, com um fundo musical, fazer-se presente a sinfonia entoada pelo canto do coro. No primeiro caso (o do texto literário), teríamos uma "imagem mental" construída pelo leitor, enquanto no segundo (o do filme) a "percepção de uma imagem visual"14.

Talvez "sugestões" dessa natureza presentes no texto de Lispector tenham despertado uma maior possibilidade de adaptação do livro de 1977 para o cinema. Contudo, não queremos dizer que, para levar a cabo determinado processo de adaptação, o texto de partida tenha que conferir possibilidades sugestivas, uma vez que estão em jogo nesse processo as escolhas, os desejos e as seduções inerentes ao cineasta, numa perspectiva mais transferencial. Pois, se a adaptação não deixa de ser um tipo de leitura tradutória do texto do outro, toda interpretação/tradução desse texto precisa ser observada a partir daquilo que o adaptador atribui a tal texto. Em outras palavras, o que lemos do texto alheio é, em amplo sentido, algo que queremos e precisamos dizer. "É nesse sentido que ler ou traduzir [“adaptar"] um texto é [...] uma forma de se estar submetido à sedução e ao desejo do outro e de comunicar o deleite

\footnotetext{
13 "O que escrevo é mais que invenção, é minha obrigação contar sobre essa moça entre milhares delas. É dever meu, nem que seja de pouca arte, o de revelar-lhe a vida" (LISPECTOR, 1984, p. 19).

${ }^{14}$ Cf. CORSEIUL, 2009, p. 371.
}

Revista Graphos, Vol. 20 n. 1, 2018 | UFPB/PPGL | ISSN 1516-1536 
e conflito envoltos nesse caso de amor" (ARROJO, 1993, p. 160) entre o cineasta e o texto de partida.

O sequestro de uma história: o narrador do texto literário e a adaptação cinematográfica

E assim se passava o tempo para a moça esta. Assoava o nariz na barra da combinação. Não tinha aquela coisa delicada que se chama encanto. Só eu a vejo encantadora. Só eu, seu autor, a amo. Sofro por ela (LISPECTOR, 1984, p. 34 - grifo nosso).

Em 1986, quase dez anos depois da publicação de A hora da estrela, de Clarice Lispector, a cineasta Suzana Amaral dirige uma adaptação fílmica de título homônimo, tomando como ponto de partida o texto da escritora. A narrativa de ambas as obras se resume à história de uma pobre moça chamada Macabéa, que saíra do sertão de Alagoas em busca de melhores condições de vida "numa cidade toda feita contra ela" (LISPECTOR, 1984, p. 21), o Rio de Janeiro. Ao chegar no "clã do sul do país", a jovem vai trabalhar de datilógrafa e dividir um pequeno quarto, situado na rua do Acre próximo ao cais do Porto, com mais quatro moças, as balconistas das Lojas Americanas (Maria da Penha, Maria Aparecida, Maria José e Maria apenas). Macabéa se apaixona pelo paraibano Olímpico de Jesus Moreira Chaves (funcionário de uma metalúrgica), contudo, logo é traída pela amiga de trabalho (Glória, “a carioca da gema"), que lhe rouba o namorado. Sem esperanças, Macabéa procura uma cartomante, engravidando-se de futuro por meio de uma esperança proveniente das previsões de madama Carlota. Porém, essa esperança de futuro logo é descartada quando a moça, ao fim da narrativa, é atropelada e morre.

A sucinta descrição do enredo faz-se necessária, pois, no filme de Amaral, há uma “transposição" muito próxima da história de Macabéa. O mesmo não podemos dizer da narrativa paralela que estrutura toda a obra de Clarice: a história fadada ao fracasso do intelectual Rodrigo S.M., que se tranca num cubículo para escrever as fracas aventuras da pobre moça. Essa narrativa realizada de forma sincopada e sobreposta à história da nordestina não é "traduzida" para a narrativa do cinema, estabelecendo uma diferença primeira entre o texto de Lispector e o filme. Entretanto, faz-se operante esclarecer que nossa leitura não preza tão somente o estabelecimento de paralelos comparativos em nome de um rastreamento das semelhanças entre os objetos em questão. 
As "diferenças" que marcam as singularidades das narrativas podem abrir caminhos reflexivos que prezem pelas idiossincrasias do filme e da novela, distante de uma busca incessante dos paralelos equivalentes. Por isso, essa escolha da cineasta não é casual. Ao entender a adaptação de A hora da estrela como um processo de tradução, estamos abrindo mão de critérios logocêntricos como o de fidelidade, já que a ideia contemporânea de tradução perdeu o antigo caráter de simples transposição de elementos, tornando-se mais uma "tradução criativa" (CAMPOS, 2010, p. 35), em contextos literários, ou uma "adaptação criativa" (DINIZ, 2005, p. 22), como sugerem os estudos de adaptação na esfera do cinema.

Na novela de Clarice, lemos inicialmente a seguinte passagem:

\begin{abstract}
A história - determino com falso livre arbítrio - vai ter uns sete personagens e eu sou um dos mais importantes deles, é claro. Eu, Rodrigo S.M. Relato antigo, este, pois não quero ser modernoso e inventar modismos à guisa de originalidade. Assim é que experimentarei contra os meus hábitos uma história com começo, meio e "gran finale" seguido de silêncio e chuva caindo (LISPECTOR, 1984, p. 18 -19).
\end{abstract}

Essa voz que narra as histórias no livro de Clarice é sequestrada na adaptação do filme de Amaral, visto que a narrativa cinematográfica parece contar-se por si só. Entretanto, não podemos nos esquecer que há, no cinema, um encarregado por organizar a diegese, cujo papel básico é deslocar a função tradicional daquele que conta, levando ilusoriamente o espectador a pensar que não há narração, mas apenas um processo de mostrar. Às vezes, esse pensamento oriundo da recepção se dá porque, ao substituir as palavras por imagens, a narração cinematográfica provoca na plateia a impressão de que as ações são assistidas sem a mediação / interferência de uma voz narrativa. Contudo, existem outras estratégias utilizadas na produção de um filme que ocupam, pensando em uma correlação entre as artes em questão, o lugar do narrador do texto literário.

Esse "sequestro" efetuado pela cineasta pode ser lido como uma das formas de borrar a noção de autoria que perpassa toda a novela de Lispector. Se, no livro, temos um narrador masculino atuante, à primeira vista, em dois planos narrativos e que se põe como "autor" das histórias narradas, podendo ser entendido como uma máscara ficcional da própria escritora Clarice Lispector - lembremo-nos da dedicatória: "Dedicatória do autor (Na verdade Clarice Lispector)" (LISPECTOR, 1984, p. 7) -; no caso do filme, essa marca autoral (oscilante, por sua vez, entre o narrador ficcional e a escritora que "realmente" escreve) não se faz presente, apesar de correlata ao processo de montagem, reiterando que a história assistida pelo espectador é adaptada a tal ponto, na obra fílmica, que a figura ficcionalizada do autor- 
narrador-personagem, por conseguinte, de sua verdadeira autora, encontra-se suprimida. Por essas razões,

[...] pode-se dizer que a presença do narrador no cinema se dá pela edição das imagens, reveladora da interferência do narrador na organização dos eventos da história. Através da edição, ou da montagem, diferentes planos, situados em um sistema espaço-temporal, podem ser articulados de forma subsequentes e sequências podem ser organizadas, não apenas linearmente, mas também numa variedade de formas. A montagem, determinada pela forma como a história é contada, aponta para a existência de um mediador que organiza os eventos da história no tempo e no espaço: o narrador. $\mathrm{O}$ termo narrador não está necessariamente associado a uma individualidade, mas revela a presença de um agente organizador da diegese, ou seja, da narrativa (CORSEIUL, 2009, p. 374).

Assim, enquanto no livro de Lispector temos um narrador que conta as várias histórias, inclusive a que representa o âmbito metalinguístico da própria obra; no filme de Amaral, a história da narrativa como exposta na tela é tramada nos bastidores das gravações e edições, sendo guiada pelos cortes e montagens efetuados pela produção (cineasta, editor, diretor, entre outros) que passa a ocupar no filme o papel singular antes encenado por Rodrigo S.M., na narrativa do livro de 1977. Dessa maneira, se na narrativa literária de Lispector faz-se presente à recepção um narrador que conta a história da escrita do próprio livro, na narrativa cinematográfica, as escolhas (ou história das montagens e edições) na construção do filme, enquanto linguagem artística, são efetivadas por instâncias que trabalham atrás das lentes das câmeras:

Sim, mas não esquecer que para escrever não-importa-o-quê o meu material básico é a palavra. Assim é que esta história será feita de palavras que se agrupam em frases e desta se evola um sentido secreto que ultrapassa palavras e frases. É claro que, como todo escritor, tenho a tentação de usar termos suculentos: conheço adjetivos esplendorosos, carnudos substantivos e verbos tão esguios que atravessam agudos o ar em vias de ação, já que palavra é ação, concordais? (LISPECTOR, 1984, p. 20 21).

(Eu ainda poderia voltar atrás em retorno aos minutos passados e recomeçar com alegria no ponto em que Macabéa estava de pé na calçada - mas não depende de mim dizer que o homem alourado e estrangeiro a olhasse. É que fui longe demais e já não posso retroceder. Ainda bem que não falei nem falarei em morte e sim apenas em atropelamento.) (LISPECTOR, 1984, p. 91). 
Figura 1- Suzana Amaral (diretora), Marcélia Cartaxo (atriz) e equipe de produção nos bastidores.

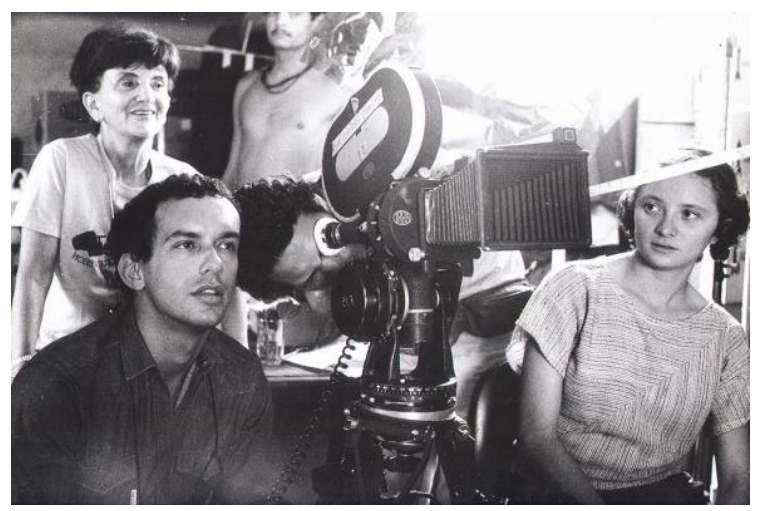

Fonte: CineAção.

Nos dois fragmentos transcritos, temos digressões narrativas realizadas por Rodrigo S.M. Na primeira, ele tece considerações sobre o próprio ato de escrita da história de Macabéa, chamando atenção para a matéria prima da criação literária: a palavra, que, na perspectiva do narrador-autor-personagem, é a responsável pela constituição das ações. No segundo, verificamos o que Jonathan Culler (1999) entende por "narração autorreflexiva". Segundo o crítico, essa estratégia narrativa é efetuada quando o narrador se põe a refletir sobre o próprio ato de narrar, afirmando a sua total segurança quanto à veracidade dos fatos e das escolhas feitas para que o enredo se transforme em discurso literário. As próprias marcas textuais, nesse caso, os parênteses que abrem e fecham as interferências de S.M. ao longo do livro, podem ser vistas como elemento indicador de pausas nas ações da história de Macabéa. É como se o narrador deixasse uma história em suspensão e passasse a refletir sobre suas eleições para que esse discurso se materialize como tal. Nesse sentido, os estudos narratológicos "falam de narrativa autorreflexiva quando os narradores discutem o fato de que estão narrando uma história, hesitam sobre como contá-la ou até mesmo ostentam o fato de que podem determinar como a história vai acabar” (CULLER, 1999, p. 89-90).

Esses recursos dos quais lança mão o narrador do texto literário correspondem, ressalvadas as diferenças, a outros mecanismos peculiares à narrativa cinematográfica dirigida por Amaral. No primeiro fragmento do texto de Clarice, temos um narrador que "conversa" com o leitor sobre seu trabalho manual com as palavras e, no segundo, uma reflexão sobre a ordem dos fatos narrados. Já no filme adaptado, as reflexões dessa natureza (como a escolha das cenas, seus encaixes narrativos, a trilha sonora e a edição das imagens) ocorrem nos bastidores das gravações. Por essa razão, a câmera passa a ocupar o lugar do narrador do texto, contudo, exercendo a função de mostrar as escolhas feitas pela produção (cineasta, Revista Graphos, Vol. 20 n. 1, 2018 | UFPB/PPGL | ISSN 1516-1536 
diretor ou editor) que adapta a história lacrimogênica de cordel, como sugere um dos títulos da novela, à tela do cinema. Assim, enquanto Rodrigo S.M. faz suas escolhas e as revela ao leitor, a câmera apenas mostra o resultado final das várias etapas (montagens) pelas quais passou a narrativa de A hora da estrela para chegar à tela do cinema. Dito de outra forma: “enquanto no filme o jogo de tensões se dá sem a verbalização do narrador, no romance a mesma cena descrita é realizada com a completa intermediação da voz do narrador" (CORSEUIL, 2009, p. 375).

Com isso, se, por um lado, temos um narrador que conta a sua história, a do outro (Macabéa) e a do próprio livro; por outro, no filme de Amaral, a história do narrador é sequestrada, as escolhas de construção narrativa efetivadas por trás das câmeras e a história de Macabéa transcriada para a tela. Talvez isso ocorra porque, segundo McFarlane, a transferência das funções distribucionais do texto literário (os pontos cruciais da narrativa) sejam as primeiras e as mais comuns a serem transpostas no processo de adaptação ${ }^{15}$. McFarlane, por meio dos estudos de análise narrativa de Roland Barthes (1976, p. 19 - 60), examina o processo de adaptação das narrativas literárias a partir de duas funções: funções distribucionais e funções integracionais.

As primeiras são, grosso modo, as ações narrativas ocorridas em determinada história e, por sua vez, se subdividem em função cardinal e função catalizadora, sendo a primeira os pontos cruciais (a linha dorsal) que estruturam o enredo e a segunda são as ações menos importantes (ações menores) que possibilitam certa veracidade e coerência ficcionais ao discurso narrativo como um todo. As segundas referem-se às informações psicológicas das personagens, à atmosfera de determinada cena, à identidade das personagens, entre outras. Essas se subdividem também em duas outras funções: as funções-índice (a psicologia das personagens e a atmosfera narrativa) e as funções-informante (os dados puros com uma significação mais imediata). Na obra dirigida por Amaral, as funções integracionais são recriadas a tal ponto que o filme adquire uma atmosfera própria, que alude, a seu modo, ao tom psicológico presente no texto de Lispector e problematizado, sobretudo, a partir das fracas aventuras de Macabéa.

\footnotetext{
${ }^{15}$ Cf. DINIZ, 2005, p. 19-20.

Revista Graphos, Vol. 20 n. 1, 2018 | UFPB/PPGL | ISSN 1516-1536
} 
Macabéa: de datilógrafa à estrela de cinema

- Sabe o que eu mais queria na vida? Pois era ser artista de cinema.
Só vou ao cinema o dia em que o chefe me paga. Eu escolho o cinema
poeira, sai mais barato. Adoro os artistas. Sabe que Marylin era toda
cor-de-rosa? (LISPECTOR, 1984, p. 62).

Existem várias passagens da novela de Lispector, a exemplo do fragmento transcrito em epígrafe, que concedem à narrativa um tom folhetinesco misturado a meios culturais e artísticos dos mais variados: rádio, cinema, jornais, revistas, músicas e publicidade. Mistura essa que faz da narrativa, segundo o próprio narrador, "uma história em tecnicolor para ter algum luxo" (LISPECTOR, 1984, p. 08). No filme, esse tom é traduzido com muita singularidade logo no início, ainda no plano da apresentação dos créditos, quando a trilha sonora alude aos anúncios da Rádio Relógio ZW-465, acompanhados pelo "tic-tac" que marca as horas ("23 horas, 0 minuto, 0 segundo") e misturados aos anúncios de curiosidades de cultura de almanaque, a exemplo da primeira pergunta feita pelo locutor da Rádio: "você sabia que a mosca é um inseto dos mais ligeiros de voar e que se ela pudesse voar em linha reta levaria 28 dias para atravessar o mundo todo?” (transcrição nossa).

No filme, assim como no texto literário, a Rádio Relógio parece ser o meio através do qual Macabéa se sintoniza com o mundo e externaliza sua pequena existência. Mesmo sem entender contextualmente as informações (anúncios e curiosidades) apresentadas pela voz que se enuncia através do aparelho movido a pilha, eram os minutos marcados pelo relógio digital da rádio os responsáveis por garantir a existência da datilógrafa, ainda que num simples e tímido sopro de vida, questão evidenciada, no filme, antes mesmo que o rosto da perdida protagonista apareça na tela. Lemos no livro:

Todas as madrugadas ligava o rádio emprestado de uma colega de moradia, Maria da Penha, ligava bem baixinho para não acordar as outras, ligava invariavelmente para a Rádio Relógio, que dava "hora certa e cultura", e nenhuma música, só pingava em som de gotas que caem - cada gota de minuto que passava. E sobretudo esse canal de rádio aproveitava intervalos entre tais gotas de minuto para dar anúncios comerciais - ela adorava anúncios. Era rádio perfeita pois também entre os pingos do tempo dava curtos ensinamentos dos quais talvez um dia viesse precisar saber. Foi assim que aprendeu que o imperador Carlos Magno era na terra dele chamado Carolus. Verdade que nunca achara modo de aplicar essa informação. Mas nunca se sabe, quem espera sempre alcança. Ouvira também a informação de que o único animal que não cruza com o filho era o cavalo.

- Isso, moço, é indecência, disse ela para o rádio (LISPECTOR, 1984, p. 45). 
Figura 2 - Macabéa ouve a Rádio Relógio durante a madrugada.

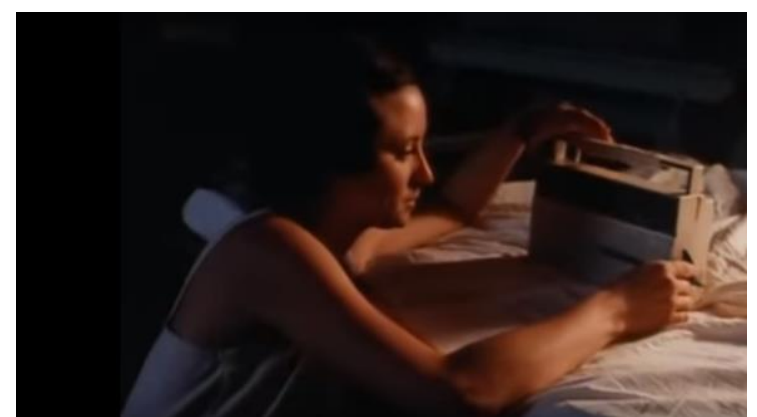

Fonte: Imagem produzida pelo próprio autor do artigo a partir do filme em estudo.

Tanto na novela quanto no filme, a Rádio Relógio parece problematizar e ao mesmo tempo mostrar ao leitor, por mediação das palavras do narrador, "a falta de um núcleo existencial de uma prévia experiência" (LISPECTOR, 1984, p. 46) que marca a vida da jovem nordestina, vida esta que, segundo S.M., "parecia uma longa meditação sobre o nada" (LISPECTOR, 1984, p. 46). Por essa razão, Macabéa, tanto na novela quanto no filme, se apresenta enquanto um não "eu" em relação a todas as outras personagens das narrativas, já que a sua fraca existência é logo posta em cena quando a protagonista começa a interagir com elementos do mundo ao seu redor, entre eles, a Rádio Relógio. As reações de Macabéa, frente aos informes ouvidos por meio do rádio, simbolizam sua inexpressividade e alienação diante de princípios banais do cotidiano de uma vida, representados no cinema, principalmente, por seu olhar acabrunhado, perdido e inocente, como se sofresse de uma moléstia existencial. Essa moléstia da qual não tem consciência é ilustrada por um incômodo do próprio viver, reproduzido, sintomaticamente, nas singelas ações da jovem que come cachorro-quente:

Ele [o médico] a examinou, a examinou e de novo a examinou.

- Você faz regime para emagrecer, menina?

Macabéa não soube o que responder.

- O que é que você come?

- Cachorro-quente.

- Só?

- Às vezes como sanduíche de mortadela.

- Que é que você bebe? Leite?

- Só café e refrigerante.

- Que refrigerante? - perguntou ele sem saber o que falar. À toa indagou:

- Você às vezes tem crise de vômito?

- Ah, nunca!, exclamou muito espantada, pois não era doida de desperdiçar comida, como eu disse.

O médico olhou-a e bem sabia que ela não fazia regime para emagrecer [...]. Ele acrescentou irritado sem atinar com o porquê de sua súbita irritação e revolta:

- Essa história de regime de cachorro-quente é pura neurose e o que está precisando é procurar um psicanalista!

Ela nada entendeu mas pensou que o médico esperava que ela sorrisse. Então sorriu (LISPECTOR, 1986, p. 76 - 77). 
Figura 3 - Macabéa, representada pela atriz Marcélia Cartaxo.

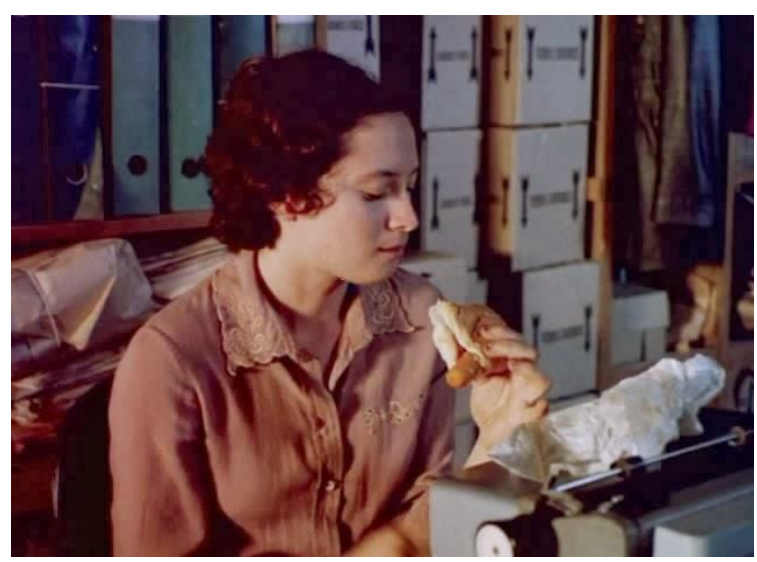

Fonte: Overdose de Entretenimento.

Devido a passagens dessa natureza, Macabéa pode ser vista como o negativo das outras personagens do filme, "espécie de tábua projetiva por excelência onde cada personagem [...] sempre estará avaliando seu lugar no mundo pela capacidade de manipulação e afirmação de poder, que pode ter este indicador final de valor de cada eu, Macabéa, aquela que não chega a ser um eu" (AB'SABER, 2003, p. 169). Entretanto, é importante lembrar que apesar das aproximações existentes entre a Macabéa do texto e a da tela, a exemplo da coerente leitura de Tales Ab'Sáber, em A imagem fria (2003), não podemos nos esquecer que o efeito desse "não eu" na recepção de ambas as obras se dá de forma distinta devido às peculiaridades que marcam a instância "personagem" nos diferentes suportes artísticos em questão. Paulo Emílio Gomes (2007) afirma que a personagem cinematográfica só começa a existir quando encarnada em uma pessoa (a atriz), já a personagem do romance existe por si só através das palavras ${ }^{16}$, ficcionalmente trabalhada por um duplo encaixe com a categoria da voz narrativa.

Assim, a cristalização definitiva de Macabéa no cinema fica condicionada a uma imagem (a visualidade), enquanto na literatura sua existência passa a ser apreendida por certa liberdade fluida manipulável pelo leitor, que pode "criar", por exemplo, uma materialidade física outra a partir do universo ficcional construído por meio de sua leitura. No cinema - a arte da presença excessiva, segundo Gomes (2007) -, essa liberdade é logo descartada, pois a materialidade da personagem é imposta na tela, de forma que o expectador se vê impossibilitado de construir uma imagem da personagem diferente daquela encarnada pela pessoa física do ator. Dessa maneira,

\footnotetext{
${ }^{16}$ Cf. GOMES, 2007, p. 111.

Revista Graphos, Vol. 20 n. 1, 2018 | UFPB/PPGL | ISSN 1516-1536
} 
As indicações a respeito de personagens, que se encontram anotadas no papel ou na cabeça de um argumentista-roteirista-diretor, constituem apenas uma fase preliminar de trabalho. A personagem de ficção cinematográfica, por mais fortes que sejam suas raízes na realidade ou em ficções pré-existentes, só começa a viver quando encarnada numa pessoa [...] (GOMES, 2007, p. 114).

Sob essa égide, Macabéa passa a adquirir uma presença na esfera narrativa do cinema somente quando representada pela atriz Marcélia Cartaxo. Cabe ressaltar que essa representação está também condicionada ao duplo papel conferido à figura do "roteiristadiretor" no que se refere à transcriação da protagonista para a tela. No caso do filme A hora da estrela, além dos agentes que trabalham atrás das câmeras exercerem a função do narrador da novela, principalmente na construção discursiva dos fatos narrados (lembremos da história da própria obra sequestrada na adaptação, mas protagonizada nos bastidores), eles ocupam também o papel de receptores do texto literário, os quais leem/traduzem/transcriam as descrições aferidas por Rodrigo S.M. a respeito da protagonista.

Um exemplo dessa espécie de filtro interpretativo/tradutório está evidente na inserção de uma “dialética da sujeira” (AB’SÁBER, 2003, p. 176) que acompanha Macabéa por todo o filme. Na obra de Clarice, o narrador acentua "o sentimento de perdição no rosto" (LISPECTOR, 1984, p. 18) e a apatia da moça com relação ao mundo que a cerca. No cinema, a figura da anti-heroína é apresentada como "uma espécie de receptáculo de toda a sujeira" (AB'SÁBER, 2003, p. 176), questão quase ausente na narrativa do livro. É como se, na Macabéa do cinema, a incompetência e a perdição fossem produtos dessa sujeira que se impregna na personagem ao longo da história, enquanto, na obra de Lispector, elas parecem mais ligadas à questão de a nordestina ser assim porque "há os que têm. E há os que não têm. É muito simples, a moça não tinha. Não tinha o quê? É apenas isso: não tinha. Se der para me entenderem, está bem. Se não, também está bem" (LISPECTOR, 1984, p. 32).

Portanto, o filme A hora da estrela, apesar de baseado em outra história ficcional, não deixa de se inscrever enquanto objeto artístico singular e específico, devido às suas particularidades de linguagem, representação e exposição. Seu processo de adaptação como tradução só vem reiterar que uma mesma narrativa, contada em um contexto (ou suporte) diferente daquele em que ela primeiro se realiza, nunca se apresentará com a mesma possibilidade de atribuições de sentidos efetivados pela recepção, seja ela de leitores ou de expectadores. Desse modo, a transcriação que a cineasta faz da obra de Clarice Lispector solicita acréscimos, suplementos, reinvenções e supressões para que a história de Macabéa 
possa ser narrada em outra esfera artística, constituindo-se como um todo coeso e coerente aberto às interpretações múltiplas em nada dependente de uma obra anterior.

\title{
Considerações finais: a adaptação como sobrevida
}

\begin{abstract}
A sobrevida das obras, mas não dos autores. Talvez a sobrevivência dos nomes dos autores e das assinaturas, mas não dos autores. Tal sobrevivência dá um pouco mais de vida, mais que uma sobrevivência. A obra não vive apenas mais tempo, ela vive mais e melhor, acima dos meios de seu autor (DERRIDA, 2002, p. 33 grifos do autor).
\end{abstract}

À guisa de conclusão das reflexões apresentadas, vemos que conceber o processo de adaptação de Suzana Amaral como tradução, seria, na perspectiva de Jacques Derrida (2002) e Walter Benjamin (2008), perceber que essa recriação do texto de Lispector no filme de 1985 promove uma sobrevida da obra da escritora, renovando-a e, ao mesmo tempo, fazendo-a presente em nossa tradição cultural. Afastando-nos de um discurso crítico que procurou pormenorizar o filme frente ao texto de Clarice $^{17}$, abordar aquele como fruto de um processo tradutório é reconhecê-lo enquanto arte responsável por conceder uma sobrevida à própria literatura, cuja vitalidade é obtida por renovações e transposições futuras erigidas ao longo da história.

Para Benjamin, a tradução (leia-se, em nosso caso, a adaptação) estabelece uma estreita relação com a obra de partida não pelo sentido que procura preservar, obtendo-o em semelhança, mas por um elo vital em que se promove a "sobrevivência" da obra. É nessa relação que, precisamente, se assegura um vínculo intertextual entre o livro e o filme, sem que aquele seja deturpado ou pormenorizado. Assim como à vida, de modo geral, é inerente um vigor abundante entre os demais viventes, "a tradução [/adaptação] nasce também do original, procedendo neste caso não tanto da vida como antes da sobrevivência da obra" (BENJAMIN, 2008, p. 27 - grifo nosso).

\footnotetext{
${ }^{17}$ Lembramos aqui do estudo de Luiza Lobo (1994) sobre o filme em questão. Para a estudiosa, "ao ser retratado na tela, este enredo [o do filme] ignora a riqueza da narração, de certos diálogos e os meios-tons da descrição, no sutil universo de significações constantes do texto de Clarice, que não podem ser transmitidos pela câmera" (LOBO, 1994, p. 65). Afirmações desse gênero tornam-se infrutíferas no contexto contemporâneo, pois acreditamos que qualquer objeto artístico, independente da relação que possui com objetos de outras naturezas, deve ser estudado por meio de valores inerentes às especificidades de sua linguagem. Assim, estudar o filme de Amaral julgando-o inferior por não conseguir fazer o que o texto literário faz, é esquecer também, em grande parte, dos recursos e efeitos propícios à arte cinematográfica, impossíveis de realização em um texto literário.
}

Revista Graphos, Vol. 20 n. 1, 2018 | UFPB/PPGL | ISSN 1516-1536 
Já que a tradução, na perspectiva benjaminiana, é processo que promove a "sobrevivência" de uma obra, a qual pode se modificar enquanto "sobrevive", metamorfose e renovação de algo com a vida ${ }^{18}$, acreditamos que o filme dirigido por Amaral, enquanto outra arte também sustentadora de uma vida própria, torna-se, por conseguinte, uma espécie de sobrevida do livro de 1977, o qual executa o processo mútuo das inter-relações entre as artes, por sinal, muito bem-vindas ao contemporâneo espaço epistêmico das teorias sem disciplinas.

\section{Referências}

AB'SÁBER, Tales A. M. A imagem fria: cinema e crise do sujeito no Brasil dos anos 80. São Paulo: Ateliê Editorial, 2003.

A HORA DA ESTRELA. Direção: Suzana do Amaral. Fotografia: Edgar Moura. [S.1.]: Raiz Produções Cinematográficas, 1985. 1 VHS (96 min).

ARROJO, Rosemary. Tradução, desconstrução e psicanálise. Rio de Janeiro: Imago Ed., 1993.

ASSIS, Machado de. Esaú e Jacó. São Paulo: Ática, 2005.

BARTHES, Roland. "Introdução à análise estrutural da narrativa". In: BARTHES, Roland [et. al.]. Análise estrutural da narrativa: seleção de ensaios da Revista "Communications". Rio de Janeiro: Vozes, 1976. p. $19-60$.

BHABHA, Homi K. O local da cultura. Tradução de Myriam Ávila, Eliana Reis e Glaucia Gonçalves. Belo Horizonte: Ed. UFMG, 1998.

BENJAMIN, Walter. “A tarefa do tradutor”. Trad. de Fernando Camacho. In: BRANCO, Lucia Castelo (org.). A tarefa do tradutor, de Walter Benjamin: quatro traduções para o português. Belo Horizonte: FALE/UFMG, 2008. p. 25 - 49. (Viva Voz). Disponível em: http://www.letras.ufmg.br/vivavoz/data1/arquivos/atarefadotradutor-site.pdf.

CAMPOS, Haroldo de. "Da tradução como criação e como crítica". In:

Metalinguagem e outras metas: ensaios de teoria e crítica literária. São Paulo: Perspectiva, 2010. (Debates). p. $31-48$.

CARVALHAL, Tania F. "Intertextualidade: a migração de um conceito". In: . $O$ próprio e o alheio: ensaios de literatura comparada. São Leopoldo (RS): Editora UNISINOS, 2003. p. $69-87$.

COMPAGNON, Antoine. O trabalho da citação. Tradução de Cleonice P. B. Mourão. Belo Horizonte: Editora UFMG, 1996.

CORSEUIL, Anelise Reich. "Literatura e cinema". In: BONICCI, Thomas; ZOLIN, Lúcia Osana (Orgs.). Teoria Literária: abordagens históricas e tendências contemporâneas. Maringá: Eduem, 2009. p. 369 - 378.

\footnotetext{
${ }^{18}$ Cf. BENJAMIN, 2008, p. 30. Revista Graphos, Vol. 20 n. 1, 2018 | UFPB/PPGL | ISSN 1516-1536
} 
CLÜVER, Claus. "Estudos Interartes: conceitos, termos, objetivos". In: Literatura e Sociedade: Revista de Teoria literária e Literatura comparada. n. 2, FFLCH, USP/São Paulo, 1997. p. $37-55$.

" "Inter textus / Inter artes / Inter media". In: Aletria: revista de estudos de literatura. n. 14. Belo Horizonte: POSLIT, Faculdade de Letras da UFMG, 2006. p. 10 - 41.

CULLER, Jonathan. "Narrativa". In: Teoria da Literatura: uma introdução. Tradução de Sandra Guardini T. Vasconcelos. São Paulo: Becca, 1999. p. 84 - 94.

DERRIDA, Jacques. Torres de Babel. Tradução de Junia Barreto. Belo Horizonte: Editora UFMG, 2002.

. "Carta a um amigo japonês". Tradução de Érica Lima. In: OTTONI, Paulo (Org.).

Tradução: a prática da diferença. Campinas, SP: Editora da UNICAMP, FAPESP, 1998. p. 19 $-26$.

DINIZ, Thaïs F. N. Literatura e cinema: tradução, hipertextualidade e reciclagem. Belo Horizonte: Faculdade de Letras da UFMG, 2005.

GOMES, Paulo Emílio Salles. "A personagem cinematográfica”. In: CANDIDO, Antonio [et. al.]. A personagem de ficção. São Paulo: Perspectiva, 2007. p. 105 - 119.

JAUSS, Hans Robert. A história da literatura como provocação à teoria literária. Tradução de Sérgio Tellaroli. São Paulo: Ática, 1994.

LISPECTOR, Clarice. A hora da estrela. 9a ed. Rio de Janeiro: Nova Fronteira, 1984.

LOBO, Luiza. "A hora da estrela: o filme e a novela". In: FILHO, Nelson Rodrigues (org.).

Letra e imagem: linguagem / linguagens. Rio de Janeiro: UERJ/Secretaria Estadual de Educação do Rio de Janeiro, 1994. p. 63 - 71.

NITRINI, Sandra. Literatura comparada: história, teoria e prática. São Paulo: Editora da Universidade de São Paulo, 2000.

NUNES, Benedito. O drama da linguagem: uma leitura de Clarice Lispector. São Paulo: Ática, 1995.

PYM, Anthony. Explorando teorias da tradução. Tradução de Rodrigo B. de Faveri, Claudia B. de Faveri e Juliana Steil. São Paulo: Perspectiva, 2017.

SAID, Roberto. "Entre o clássico e o contemporâneo: metacinema em Greenaway". In: Papéis: Revista de Letras. v. 9, n. 18. Campo Grande: Ed. UFMS, 2005. p. 12 - 17.

SOUZA, Eneida Maria de. Tempo de pós-crítica. São Paulo: Linear B; Belo Horizonte: Veredas e Cenários, 2007.

WELLEK, René; WARREN, Austin. Teoria da Literatura. Tradução de José Palla e Carmo. s.l.: Publicações Europa-América, s.d.

Recebido em 29/06/2018

Aceito para publicação em 30/07/2018 